\title{
Stroke after tadalafil use
}

\section{Emanuele Cannizzaro, Carla}

\section{Cannizzaro, Gianluca Lopez \& Daniele Lo Coco}

Neurological Sciences

Official Journal of the Italian

Neurological Society

ISSN 1590-1874

Neurol Sci

DOI 10.1007/s10072-013-1324-x

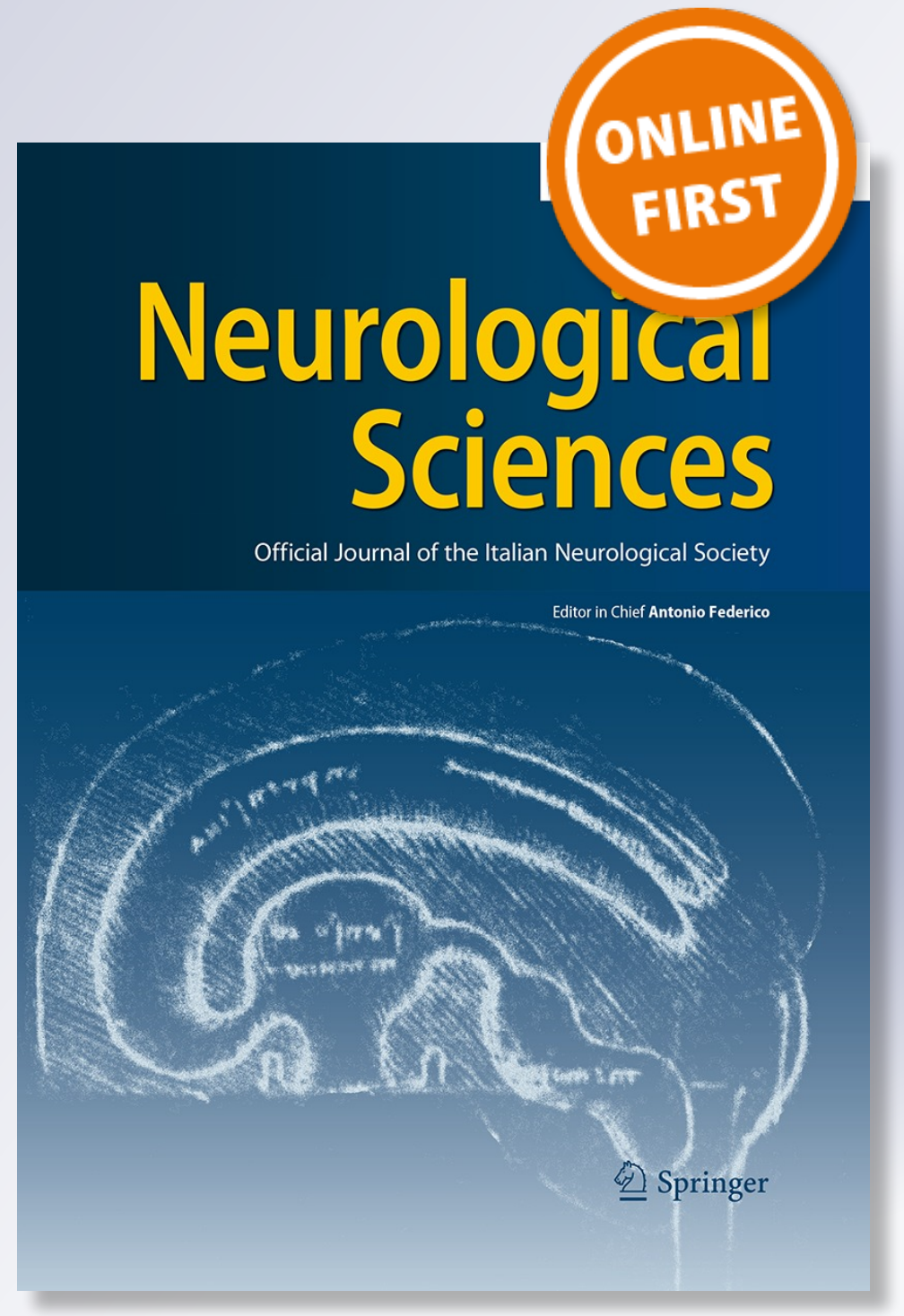

留 Springer 
Your article is protected by copyright and all rights are held exclusively by Springer-Verlag Italia. This e-offprint is for personal use only and shall not be self-archived in electronic repositories. If you wish to self-archive your work, please use the accepted author's version for posting to your own website or your institution's repository. You may further deposit the accepted author's version on a funder's repository at a funder's request, provided it is not made publicly available until 12 months after publication. 


\section{Stroke after tadalafil use}

\author{
Emanuele Cannizzaro $\cdot$ Carla Cannizzaro • \\ Gianluca Lopez • Daniele Lo Coco
}

Received: 10 December 2012/ Accepted: 23 January 2013

(C) Springer-Verlag Italia 2013

Keywords Stroke - Tadalafil · Phosphodiesterase inhibitors $\cdot$ Cerebral infarction

Tadalafil, a phosphodiesterase type 5 (PDE5) inhibitor, which augments cyclic guanine monophosphate in the central nervous system, has been shown to increase neurogenesis, angiogenesis, and synaptogenesis, and to improve functional outcomes compared with placebo in a rat model of ischemic stroke [1].

Sildenafil, another PDE5 inhibitor, also showed similar effects in preclinical studies of stroke models in the rat [1]. Although infrequently, sildenafil has been also associated with serious cardiovascular events such as ischemic stroke, intracerebral hemorrhage, and anterior ischemic optic neuropathy [2-6]. There is only one study reporting an association between tadalafil usage and stroke [7]. Here, we describe a patient who sustained a subcortical infarction after tadalafil use.

A 52-year-old man was admitted to our institution because of right facial weakness, slurred speech, and right hemiparesis developed about $2 \mathrm{~h}$ after taking $10 \mathrm{mg}$ of tadalafil without participating in sexual intercourse. Four months before the beginning of the present complaints, after he had ingested the first and only other dose of $10 \mathrm{mg}$ of tadalafil, he experienced the same neurologic symptoms,

E. Cannizzaro - C. Cannizzaro

Dipartimento Per La Promozione Della Salute

“G. D’Alessandro”, Università di Palermo, Palermo, Italy

G. Lopez · D. Lo Coco $(\square)$

U.O. Neurologia e Stroke Unit, Dipartimento di Neuroscienze, Ospedale Civico-ARNAS, P.za N. Leotta 4,

90127 Palermo, Italy

e-mail: danielelococo@yahoo.com again without achieving an erection or participating in sexual intercourse. In that occasion, however, his symptoms slowly returned to baseline over $1 \mathrm{~h}$.

On admission to our hospital, the neurologic examination showed that the patient was mildly dysarthric, had right lower facial weakness, 3/5 strength (Medical Research Council Scale) in his right upper extremity, and $4 / 5$ strength in his right lower extremity. Sensory examination and coordination tests were normal. His medical history was normal, and he was taking no medications. He was a non-smoker and did not drink alcohol. His blood pressure and the cardiovascular examination were normal. Brain MRI performed the day after admission demonstrated an acute/subacute infarction of the posterior limb of the left internal capsule (Fig. 1). On magnetic resonance angiography there were no significant stenoses of extracranial or intracranial vessels. Cardiac evaluation including heart ultrasound was normal. Immunologic tests and screening for thrombophilias were also normal. A therapy with $300 \mathrm{mg}$ of aspirin per day was started for 1 week, and was then reduced to $150 \mathrm{mg}$ per day.

After 1- and 2-year follow-up, the patient showed good recovery. He did not take tadalafil or others PDE5 inhibitors and did not suffer more stroke episodes.

Oral PDE5 inhibitors (sildenafil, vardenafil, tadalafil) are the recommended first-line therapy for erectile dysfunction [8]. All three PDE5 inhibitors share a common mechanism of action, preventing cyclic guanosine monophosphate (cGMP) breakdown. Sildenafil and vardenafil have similar molecular structures, but tadalafil is structurally different, which is reflected in its pharmacokinetic profile and its selectivity for PDE isozymes [8]. All three PDE5 inhibitors are rapidly absorbed from the gastrointestinal tract and peak plasma concentrations of tadalafil are reached after approximately $2 \mathrm{~h}$. Sildenafil and 


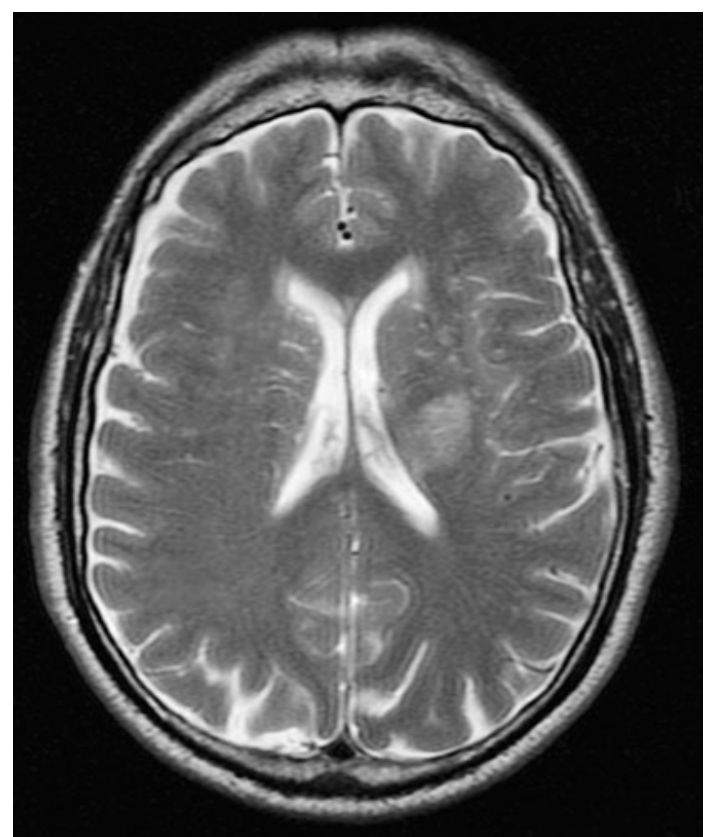

Fig. 1 Brain MRI showing small round lesion, hyperintense in T2weighted sequences, located in the posterior limb of the left internal capsule and extending to the caudate nucleus, consistent with an acute/subacute infarct

vardenafil both have a terminal half-life of approximately $4 \mathrm{~h}$, and tadalafil has a half-life of $17.5 \mathrm{~h}$ [8].

Class-specific side effects include headache, flushing, nasal congestion, dyspepsia and myalgia [8]. PDE5 inhibitors use is not recommended in men who have recent history of stroke or myocardial infarction (within the last 6-8 weeks), or who have significantly low blood pressure, uncontrolled high blood pressure, unstable angina, severe cardiac failure, severe liver impairment or end-stage kidney disease requiring dialysis. Moreover, both sildenafil and tadalafil have been associated with an increased risk of non-arteritic anterior ischemic optic neuropathy [6], but sildenafil has been also recently linked to transient ischemic attack, ischemic stroke and intracerebral hemorrhage [2-5].

This report, describing a patient that developed an ischemic stroke $2 \mathrm{~h}$ after ingesting $10 \mathrm{mg}$ of tadalafil, emphasizes that ischemic cerebrovascular events, although rarely, may develop after exposure to multiple PDE5 inhibitors, not only sildenafil [7].

Many findings from our report strongly support a causal relationship between the symptoms of the patient and tadalafil: (1) the time range between the assumption of tadalafil and the occurrence of ischemic stroke is consistent with the pharmacokinetic of the drug; (2) the patient experienced the same symptomatology in both the occasions of tadalafil ingestion; (3) in the two following years of follow-up the patient abstained from PDE5 inhibitors use, and had no clinical cerebrovascular events. However, the lack of transesophageal echocardiography and prolonged cardiac monitoring, prevent the definitive exclusion of an independent cardioembolic source. The mechanism by which tadalafil induced symptomatic cerebrovascular disease in our patient remains not fully understood. As in a previous report, a transient lowering of blood pressure is the most suggestive cause of our patient's symptoms, although a cardioembolic source, provoked by a transient brief atrial fibrillation is also plausible [2, 4].

In conclusion, our case suggests that cerebrovascular ischemic events, even if uncommon adverse effects, should be taken into consideration by the physicians prescribing this drug, especially in the presence of other stroke risk factors. Future studies should deeply investigate this serious and potentially life-threatening association.

Conflict of interest The authors have indicated no financial conflicts of interest.

\section{References}

1. Zhang L, Zhang Z, Zhang RL, Cui Y, LaPointe MC, Silver B, Chopp M (2006) Tadalafil, a long-acting type 5 phosphodiesterase isoenzyme inhibitor, improves neurological functional recovery in a rat model of embolic stroke. Brain Res 1118:192-198

2. Morgan JC, Alhatou M, Oberlies J, Johnston KC (2001) Transient ischemic attack and stroke associated with sildenafil (Viagra) use. Neurology 57:1730-1731

3. Habek M, Petravić D (2006) Stroke-an adverse reaction to sildenafil. Clin Neuropharmacol 29:165-167

4. Kim KK, Kim DG, Ku YH, Lee JY, Kim WC, Kim OJ, Kim HS (2008) Bilateral cerebral hemispheric infarction associated with sildenafil citrate (Viagra) use. Eur J Neurol 15:306-308

5. Alpsan MH, Bebek N, Ciftci FD, Coban O, Bahar S, Tuncay R (2008) Intracerebral hemorrhage associated with sildenafil use: a case report. J Neurol 255:932-933

6. Carter JE (2007) Anterior ischemic optic neuropathy and stroke with use of PDE-5 inhibitors for erectile dysfunction: cause or coincidence? J Neurol Sci 262:89-97

7. Stefanović-Budimkić M, Jovanović DR, Beslać-Bumbaširević L, Ercegovac MD (2012) Recurrent ischemic stroke associated with sildenafil and tadalafil use in a young adult. Clin Neurol Neurosurg 114:405-407

8. Wright PJ (2006) Comparison of phosphodiesterase type 5 (PDE5) inhibitors. Int J Clin Pract 60:967-975 